\title{
Urdimento
}

Revista de Estudos em Artes Cênicas

E-ISSN: 2358.6958

\section{La Partitura como Máscara: uma experiência em mascaramento espacial na Universidad de Costa Rica}

\author{
Ipojucan Pereira Silva
}

\section{Para citar este artigo:}

SILVA, Ipojucan Pereira. La Partitura como Máscara: uma experiência em mascaramento espacial na Universidad de Costa Rica. Urdimento, Florianópolis, v. 2, n. 38, ago./set. 2020.

DOI: http:/dx.doi.org/10.5965/14145731023820200026

Este artigo passou pelo Plagiarism Detection Software | iThenticate 
La Partitura como Máscara:

uma experiência em mascaramento espacial na Universidad de Costa Rica

Ipojucan Pereira Silva ${ }^{1}$

\begin{abstract}
Resumo
Fruto da pesquisa de doutorado Mascaramento Espacial: um processo criativo envolvendo a espacialidade corporal do ator, o artigo apresenta as etapas de um processo de criação realizado na Escuela de Artes Dramáticas de la Universidade de Costa Rica (EAD-UCR), no qual a espacialidade corporal do ator serve de matriz principal para a constituição de seu discurso cênico. Os resultados apontam para procedimentos metodológicos baseados na maneira como a ambiência margeia um percurso que parte das dinâmicas e qualidades de movimento, e repercute, posteriormente, tanto na criação de ações cênicas quanto na organização dessas em partituras físicas.
\end{abstract}

Palavras-Chave: Mascaramento. Espacialidade. Corporalidade. Atuação.

\title{
La Partitura como Máscara:
}

an experience in spatial masking at the Universidad de Costa Rica

\begin{abstract}
As a results of the doctoral research Mascaramento Espacial: um processo criativo envolvendo a espacialidade corporal do ator, the article presents the stages of a creative process carried out at Escuela de Artes Dramáticas de la Universidade de Costa Rica (EAD-UCR), in which the bodily spatiality of the performer serves as a main matrix to construct their performance. The results point to methodological procedures based on the way the ambience bordering a path that comes from the dynamics and qualites of the movements, and subsequently affects both the creation of scenic actions and the organization these actions in physical scores.
\end{abstract}

Keywords: Masking. Spatiality. Embodiment. Performance. 
A figura mecânica e artificial da marionete, ou do boneco articulado, tornouse na primeira metade do século XX um recurso expressivo importante para uma geração de artistas europeus. Esse expediente passou a ser o centro de um processo que transformava o corpo do intérprete e o reorganizava tecnicamente segundo as suas leis funcionais. Heinrich Von Kleist, por exemplo, tomou a dinâmica de movimento da marionete como um parâmetro para o bailarino, para que este alcançasse a perfeição técnica e a harmonia expressiva ao se concentrar apenas na mecânica do corpo, evitando as interferências do pensamento e das emoções.

A forma mais acessível de se trabalhar no corpo do ator os princípios da marionete é o mascaramento, que nas poéticas de vários dos criadores que viveram nas primeiras décadas do século passado assumiu uma presença fundamental nas suas pesquisas. As investigações da máscara na formação do ator feitas por Jacques Copeau, as experimentações vanguardistas de transformação da plasticidade do corpo por meio de cenários e figurinos abstratos, são exemplos dessa busca, de um incremento na expressividade física por intermédio da conjugação de elementos que funcionavam como máscaras corporais:

No início do século XX, as novas teorias da cena buscavam um ator novo, um corpo teatral livre das convenções da verossimilhança psicológica e da representação ilusionística: uma forma plástica, integrada ao cenário, material entre outros materiais, adaptável a pronunciar um texto que, por sua vez, não segue mais as normas da convenção linguística. [...] A marionete, [...] um corpo artificial [...] com centros gravitacionais deslocados e centrípetos, torna-se o corpo teatral por excelência [...], um corpo que não se propõe a "representar" uma realidade interior ou sensorial [...] Um corpo que não entra na convenção da ilusão do verossímil, mas que se propõe como uma tela que acolhe as imagens projetadas pelo espectador." (Eruli, 2008, p. 19-20, grifo do autor).

Uma proposta teatral inspirada na marionete pressupõe, entre outras coisas, numa dissociação entre os elementos expressivos - como, por exemplo, entre o personagem e a sua voz, que provém do manipulador ou de alguma mídia previamente gravada -, os quais são rearranjados e organizados na constituição da "verdadeira imagem [...], [que] é a mental, reconstruída por cada espectador na 
própria imaginação a partir [...] [desses] elementos sugeridos pela cena” (Eruli, 2008, p. 16). A distorção da voz, a objetividade dos impulsos internos, a articulação de um outro eixo postural são algumas condições oferecidas pelo mascaramento proporcionado por meio do jogo com o boneco, no qual o mínimo exigido é a ampliação da gestualidade do intérprete.

Existem vários caminhos para se iniciar um trabalho prático a partir dessas questões, porém um dos princípios que fundamentam qualquer uma das metodologias é de que a ilusão de vida conseguida por meio da animação, de qualquer matéria inanimada, requer do manipulador um estado de energético diferenciado do seu habitual. Para o ator isso significa a construção de uma corporeidade adequada para cada tipo de mascaramento que ele venha a realizar em cena. A indicação da qualidade do tônus, do ritmo, da postura, etc., está disposta nas questões formais apresentadas pelo tipo de mascaramento.

Os procedimentos que são aplicados procuram encaminhar a observação do ator para o conflito plasmado nas incongruências, ambiguidades e oposições das linhas e relevos presentes no material investigado. O foco sempre recai no incremento do potencial de caracterização física por meio da adaptação da corporalidade aos desenhos e traços das formas. O caminho é conhecer e reproduzir por meio de gestos, posturas corporais, entonações na fala e modos de se comportar e agir, as regras, os ritmos, as intenções presentes no parceiro inanimado. Essa metodologia de criação a partir da observação e experimentação corporal das características físicas e concretas do objeto vem a ser fundamental para a abordagem criativa de qualquer mascaramento.

O mascaramento teatral ajuda o ator na comunicação do caráter da personagem ou na materialização de algo impalpável, como o espaço. Quanto menos mimético ao mundo natural, maior a potencialidade do mascaramento em representar conceitos espaciais, pois a abstração pode tanto evocar características essenciais da natureza quanto falar de uma não-realidade. Mascaramentos abstratos têm a capacidade de ajudar na fisicalização do espaço pelo atuante, levando-o a ver o ambiente como consequência da sua própria espacialidade corporal. 
A partir de jogos e improvisos se estabelece um estado de abertura e prontidão para os estímulos, bem como uma primeira abordagem das relações que o tipo de mascaramento estabelece entre a sua geometria e o espaço ao redor, seja ele arquitetônico ou humano. O resultado disso é uma dilatação da presença do ator quando se instala um estado físico de atenção e prontidão, "o ponto zero, momento de energização e de escuta que antecede a ação, pausa antes de agir" (Amaral, 2002, p. 43-44) que abre a percepção do atuante para o tempo presente dos acontecimentos do ambiente. Tal condição vem a ser um instrumento importante para potencializar a presença, ao se criar uma disponibilidade que pode ser associada a um esvaziamento de qualquer prédisposição para a ação, tornando assim a motivação bastante reativa aos impulsos.

\section{A oficina La Partitura como Máscara}

Tive a oportunidade de aplicar, em uma oficina de curta duração que cobriu um período de dois dias, algumas rotinas de trabalho com foco no mascaramento como operador na utilização do espaço como parâmetro de criação para o ator. Essa oficina, intitulada La Partitura como Máscara, foi ministrada na Escuela de Artes Dramáticas de la Universidad de Costa Rica (EAD-UCR), com os alunos de graduação dos primeiro e segundo anos de artes cênicas, em agosto de 2014. Vale ressaltar que os procedimentos de mascaramento aplicados, com o objetivo de potencializar a relação corpo/espaço como matriz geradora de ações, foram resultado das investigações práticas realizadas nos laboratórios de criação cênica para a minha pesquisa de doutorado Mascaramento Espacial: um processo criativo envolvendo a espacialidade corporal do ator (2015), realizados no Centro de Pesquisa em Experimentação Cênica do Ator (CEPECA) do Departamento de Artes Cênicas da ECA-USP.

Na oficina La Partitura como Máscara objetivou-se, de maneira breve e sintética, propiciar uma introdução aos princípios do mascaramento espacial, a partir da utilização da partitura como máscara, compreendendo um diálogo entre o espaço pessoal (corpo) e o ambiente. Nessa abordagem, a corporeidade foi 
tomada como base para um pensamento sobre a espacialidade, a partir do diálogo entre as características cinéticas do orgânico e do inorgânico, sendo dividida didaticamente em três camadas concêntricas de percepção e dinamismo: espaço em si (interno ao corpo), espaço fora de si (externo/próximo ao corpo) e espaço além de si (externo/distante do corpo).

Contando com o apoio de suportes diversos, tais como imagens, sonoplastia e de exercícios pré-expressivos, baseados tanto no Sistema dos Viewpoints ${ }^{2}$ quanto no treinamento preparatório para a máscara neutra, foram experimentados princípios de construção, organização e execução de pequenas partituras cênicas cuja finalidade era o seu funcionamento como mascaramento nos jogos de cena e na relação com o espectador. Essa experiência artísticopedagógica, no formato concentrado de uma oficina, possibilitou submeter ao exame, em diferente contexto, o comportamento e a eficácia de alguns procedimentos e metodologias experimentados e desenvolvidos na pesquisa de doutorado.

Foi bastante difícil conseguir um aprofundamento mínimo das propostas desenvolvidas nas investigações laboratoriais do doutoramento - que tiveram um tempo de experimentação generoso de um ano para o trabalho com esses conteúdos -, frente ao tempo destinado para as atividades da oficina, de apenas dois encontros de quatro horas cada, divididos em dois dias. Dessa maneira, a abordagem pedagógica foi reformulada para que o aluno explorasse uma via de mão dupla: perscrutar a forma (incorporando a energia proposta) e motivar em si a intensidade vibratória (colocar a forma em ação). O planejamento dos encontros estabeleceu como ponto de partida a conscientização das potencialidades do próprio corpo, passando ao trato com o potencial expresso em outro corpo (a

2 "Os Viewpoints físicos se subdividem em duas categorias: os Viewpoints de Espaço (Forma, Relação Espacial, Gesto, Topografia e Arquitetura) e os Viewpoints de Tempo (Ritmo, Duração, Repetição e Resposta Cinestésica). [...] Os Viewpoints relacionados ao Espaço buscam mapear as diferentes ignições do ambiente de trabalho, numa dinâmica em que o próprio corpo e gestualidade do ator estão diretamente relacionados a outros corpos, objetos e estruturas concretas do espaço. [...] Os Viewpoints de Tempo procuram enfatizar o elemento cronológico das ações a partir do constante cruzamento entre as diferentes percepções, como a auditiva e a sensorial, e entre essas e a materialidade do espaço. Tanto a movimentação produzida pelo ator quanto os acontecimentos do grupo são, nessa perspectiva, elementos que podem sofrer alterações de acordo com as pausas, as acelerações e o dilatamento do tempo, num jogo em que o espaço evidentemente também adquire outras nuances." (Silva, 2013, p. 19-20). 
forma).

\section{Etapa 1: Pré-expressividade e explorações perceptivas}

Para o aquecimento foi proposto algo bem simples. Os participantes foram convidados a fazerem uma caminhada pela sala, como uma primeira abordagem perceptiva entre o espaço pessoal e o espaço além de si mesmo, que era constituído pelos outros corpos e pela arquitetura do ambiente. Para dar relevo a esse trabalho pré-expressivo, a turma foi reunida numa grande roda para a realização de alguns exercícios de foco e campo visual baseados no Sistema dos Viewpoints, nos quais foram trabalhadas a visão periférica e a atenção ao que estava acontecendo tanto no espaço fora de si quanto além de si mesmo. A razão de um aquecimento psicofísicos baseados no Viewpoints decorre do fato desse sistema possuir um número expressivo de procedimentos centrados na percepção do ator, tanto de si quanto do todo, fundamentados em "certos princípios de movimento baseados no tempo e no espaço [...] [e que] representam pontos de conscientização que um artista ou criador faz uso durante o seu processo criativo 3" (Bogart, 2005, p. 08), com vistas ao treinamento, improvisação e composição cênicos.

Dentro da metodologia do Viewpoints, os jogos e exercícios de aquecimento objetivam a atenção e a conexão entre os participantes, o que faz com que esses procedimentos serem geralmente aplicados em grupo, relacionando essa condição à percepção ampliada do espaço no qual se desenvolve a prática. Como o objetivo era propiciar um conjunto de procedimentos que, sem fazer o uso da máscara propriamente dita, pudessem levar os participantes a investigarem alguns dos estados propiciados pelo mascaramento, foram escolhidos para as sessões de trabalho dois eixos exploratórios que estruturam uma série de exercícios do Sistema dos Viewpoints (ver Figura 1): a escuta extraordinária4 - "significa ouvir

3 [...] certain principles of movement through time and space [...] Viewpoints is points of awareness that a performer or creator makes use of while working. (Tradução nossa)

"Capacidade de o ator reagir com o corpo todo aos diversos estímulos; princípio voltado à "reação" do performer em detrimento da motivação interior ou psicológica. Ativam-se as capacidades intuitivas e o 
com todo o corpo, sem uma ideia prévia do resultado [...], a fim de agir de acordo com o instinto e a intuição5" (Bogart, 2005, p. 33) -, e o foco suave6 , um "estado físico no qual os olhos suavizam e relaxam de modo que, [...] os participantes são levados a olhar o espaço e os outros sem desejo".? (Bogart, 2005, p. 31, grifo do autor).

Figura 1 - Sistema dos Viewpoints: exercícios de escuta extraordinária e foco suave. Oficina La Partitura como Máscara (2014)
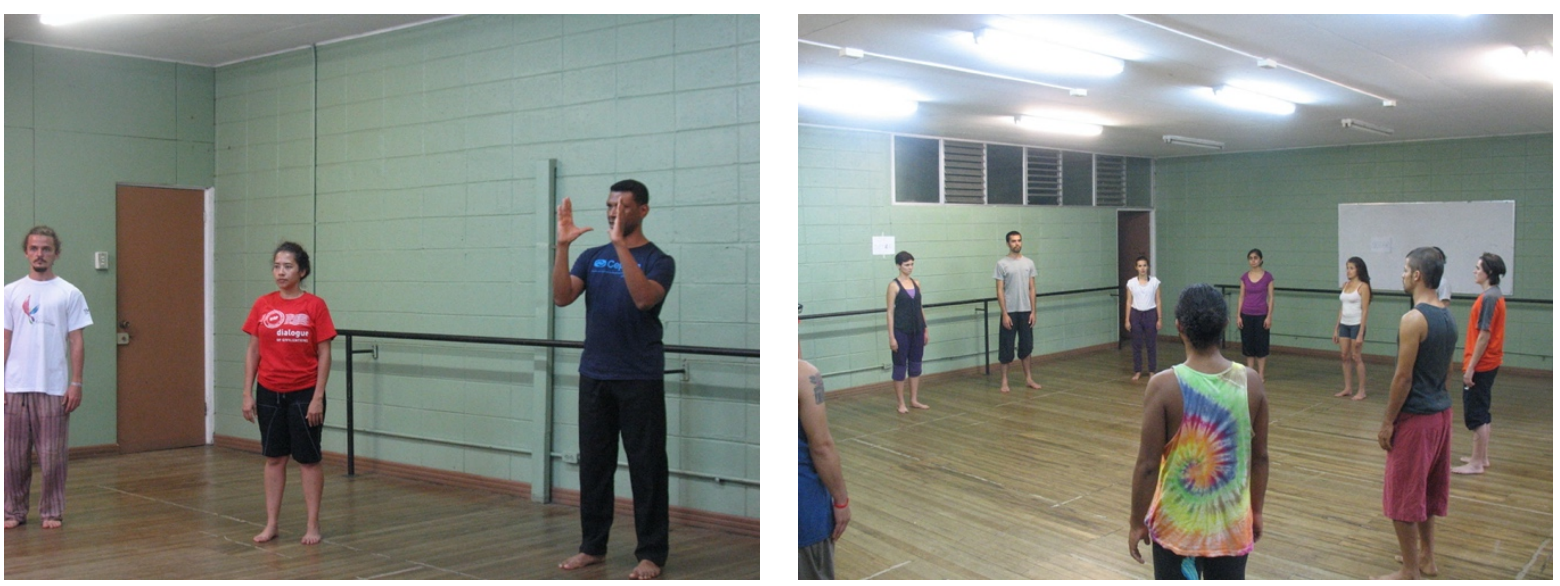

Foto: Ipojucan Pereira

A maior parte dos exercícios desenvolvidos para o treinamento préexpressivo estavam ligados aos Viewpoints de Espaço que, segundo Anne Bogart (2005), envolvem basicamente o contorno ou delineamento do corpo no espaço e sua gestualidade, resultante do seu relacionamento com a arquitetura e da sua conexão com outros corpos. A percepção sobre a topografia do ambiente - as massas sólidas, texturas, luzes, cores e sons etc. - traz a consciência tanto sobre a forma como a paisagem afeta os movimentos corporais quanto abrange a

estado de prontidão, e passa a haver disponibilidade e abertura aos demais elementos da cena." (Silva, 2013, p. 61, grifo do autor).

5 [...] means listening with the whole body without an idea of the result [...], in order to act upon instinct and intuition. (Tradução nossa)

6 “Investigação do 'olhar', que deve estar ampliado em $360^{\circ}$ para que tudo o que venha a acontecer na cena possa ser percebido pelo ator. [...] um modo de olhar [...] que não é fixo ou voltado a algo externo, mas que negocia dinamicamente com as transformações internas que também vão ocorrendo. [...] um estado de maior receptividade para com as possíveis influências externas." (Silva, 2013, p. 61, grifo do autor).

Soft focus is the physical state in which we allow the eyes to soften and relax so that, [...] the participants are asked to look at the surroundings and at other people without desire. (Tradução nossa) 
planimetria do chão criada pelos deslocamentos.

O trabalho para o segundo encontro da oficina foi iniciado com um aquecimento pré-expressivo que já colocasse em xeque a atenção às questões de tempo e espaço relativas aos deslocamentos do corpo. Numa roda formada pelos participantes, um deles estabelecia um contato visual com alguém do círculo, sem combinação prévia, para então cruzar a roda na direção daquele que foi olhado. Esse, deveria buscar fazer contato visual com qualquer outro integrante da roda e se dirigir na sua direção, antes que aquele que fez inicialmente contato visual com ele chegasse ao seu lugar. A manutenção desse fluxo de trocas garantiria que sempre àquele que se desloca encontrar o lugar desocupado na roda para ser preenchido por si.

Como instrução geral, todos os jogadores deveriam estar conectados ao que se passava, já que qualquer um poderia ser convocado pelo olhar de alguém a se deslocar do seu lugar para um outro. Depois de um tempo, foram propostas algumas variações dinâmicas para essas trocas de lugares, que traziam de volta a lembrança das experimentações com as transformações de movimento exploradas no primeiro encontro, tais como: variar o ritmo das trocas de lugares; introduzir pausas durante o trajeto; mudar a trajetória durante o percurso etc.

O trabalho reflexivo e prático de cada ator sobre a relação entre o seu corpo, a arquitetura da sala de ensaio e as atividades dos outros atores compreendeu as etapas: foco e campo visual; consciência da presença do outro no espaço; relações entre corpo e arquitetura; o outro como arquitetura; e dinâmicas criadas pelos outros corpos. Esses estágios se complementavam na busca de uma percepção sobre as composições espaciais que se dão entre os indivíduos presentes no ambiente e estruturas arquitetônicas.

Inicialmente, o estímulo dado foi direcionado para a consciência permanente no tempo e no espaço da dinâmica dos corpos, a fim de experimentar a execução de ações simples em conjunto, tais como andar, parar, girar etc., e sem nenhum tipo de comando prévio. Depois, a partir de uma conexão estabelecida, o grupo passa a andar pela sala aleatoriamente, porém atento às conformações espaciais resultantes dos deslocamentos, dispersões e aglutinações das pessoas no espaço. 
A busca é pela observação dos movimentos e ritmos que acontecem incessantemente. A atenção recai sobre as sensações físicas decorrentes das dinâmicas geradas pelos movimentos e mudanças de posição dos corpos. Esse jogo propicia um estímulo ao pensamento de como organizar os elementos ao redor de si e em uma relação com as massas sólidas. Com os deslocamentos pelo espaço, aos poucos o ator expande o campo visual para incluir o outro. Observase o ambiente como se o outro criasse um novo espaço somente com suas dinâmicas, isto é, entre duas pessoas e seus deslocamentos podem aparecer vãos ou brechas a serem atravessadas.

\section{Etapa 2: Um diálogo entre a partitura e o espaço pessoal (corpo)}

Aprofundando o trabalho sobre a espacialidade corporal, problematizei as relações entre o espaço pessoal (espaço em si e fora de si) e o espaço além de si mesmo. Como ponto de partida para essas investigações, tomei como base o pensamento para a delimitação espacial proposto por Rudolf Laban por meio da cinesfera, entendida por ele como "a esfera de espaço em volta do corpo do agente na qual e com a qual ele se move. [...] Cinesfera é a esfera pessoal de movimento. Determina o limite natural do espaço pessoal.” (Rengel, 2003, p.32).

Didaticamente, a imagem da cinesfera parecia um expediente pedagógico bastante eficaz que poderia ajudar o aluno na exploração do seu espaço pessoal. Utilizou-se algumas vezes como imagética a ideia de uma bolha maleável e flexível, ou mesmo uma nuvem amorfa que se molda de acordo com a energia que the é aplicada. Porém, o emprego desse recurso exigiu a sua adaptação a uma corporeidade que também deveria ser vista como irradiadora de seu próprio espaço, gerado como um campo que se expande e se contrai numa variabilidade muito mais atrelada dinâmica do corpo, o que consequentemente não o condiciona a uma estrutura formal regular e homogênea como a da esfera.

A solução foi trabalhar com reproduções fotográficas de esculturas. Como instrução inicial, os alunos foram convidados a realizarem uma apreciação dessas imagens, espalhadas pelo chão da sala de ensaio (ver Figura 2). O foco de 
observação principal foi relativo às direções assumidas pelos membros e partes dos corpos escultóricos no espaço. Após um período de sobrevoo sobre as figuras, foi pedido que cada um escolhesse uma delas para plasmar em seu próprio corpo. Nessa etapa, o aluno começa a investigar o seu espaço pessoal.

Figura 2 - Estudo das direções assumidas pelos membros e partes dos corpos escultóricos no espaço. Oficina La Partitura como Máscara (2014)

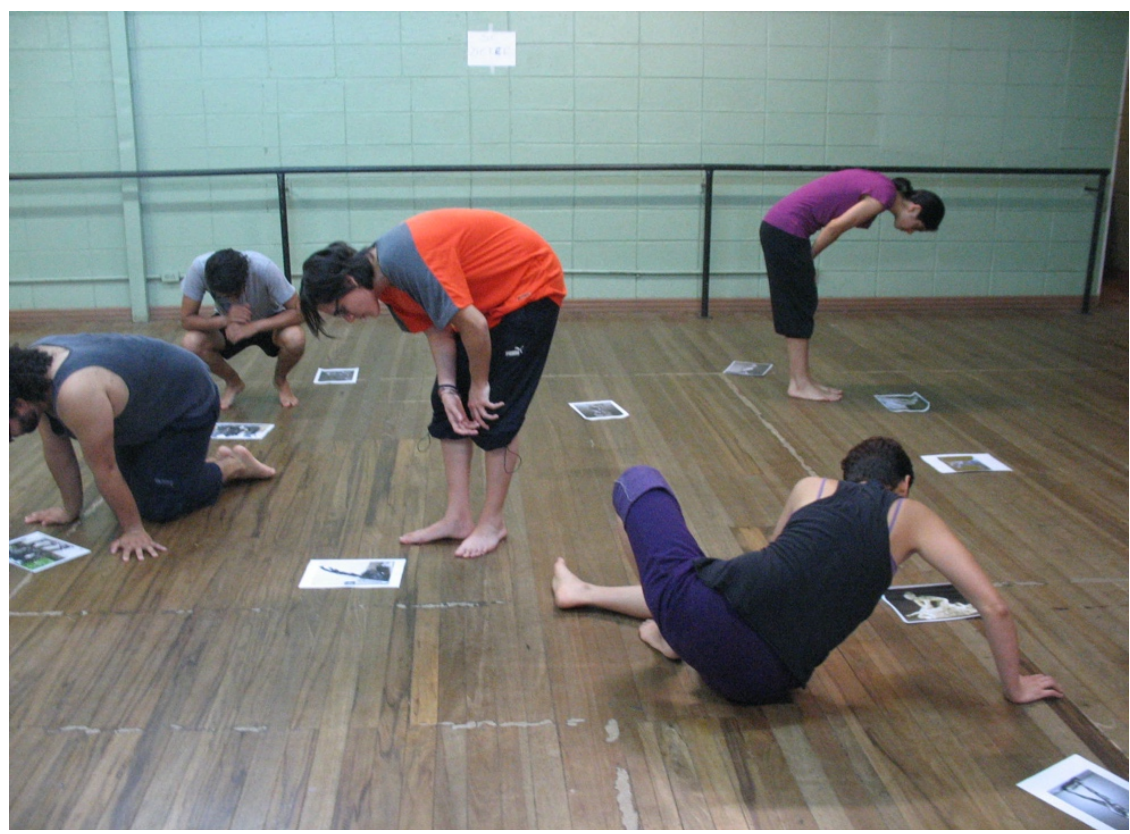

Foto: Ipojucan Pereira

Uma base importante para esse processo é o espelhamento. Sejam quais forem regras ministradas para o processo de instauração de um mascaramento, a observação do elemento utilizado como máscara é orientada tanto para ser um vetor de percepção de si mesmo, quanto como se este estivesse diante de um espelho que exibe uma imagem diversa da sua própria identidade. No desenvolvimento dessa proposta, as instruções dadas objetivam que o corpo funcione como um reflexo dessa alteridade, buscando um espelhamento fiel do que é visto. Dessa maneira, o humano se deixa habitar pela forma, entrega-se ao seu controle sem premeditar as ações, passando a ser conduzido por ela durante a caracterização.

Sem se deslocar pelo ambiente da sala, cada um fixou a postura da escultura 
escolhida, e a partir dessa forma assumida pela fisicalidade, deu início à exploração do desenvolvimento da trajetória do movimento do próprio corpo no espaço, sendo pedido como procedimento a cada um dos participantes que criasse uma sequência de ações simples, com começo, meio e fim, a partir da escolha de uma delas (ver Figura 3). Todas as imagens escultóricas representavam posturas físicas, que deveriam ser encaradas como o ponto médio de uma provável trajetória do corpo pelo espaço, durante o desenvolvimento de uma ação qualquer. A postura fixada foi tratada como o ponto médio numa sequência de fotogramas, cabendo ao participante descobrir quais outras posturas possíveis poderiam representar o início e o fim dessa sequência de movimento.

Figura 3 - Estudo das direções dos corpos escultóricos por meio da própria fisicalidade. Oficina La Partitura como Máscara (2014)

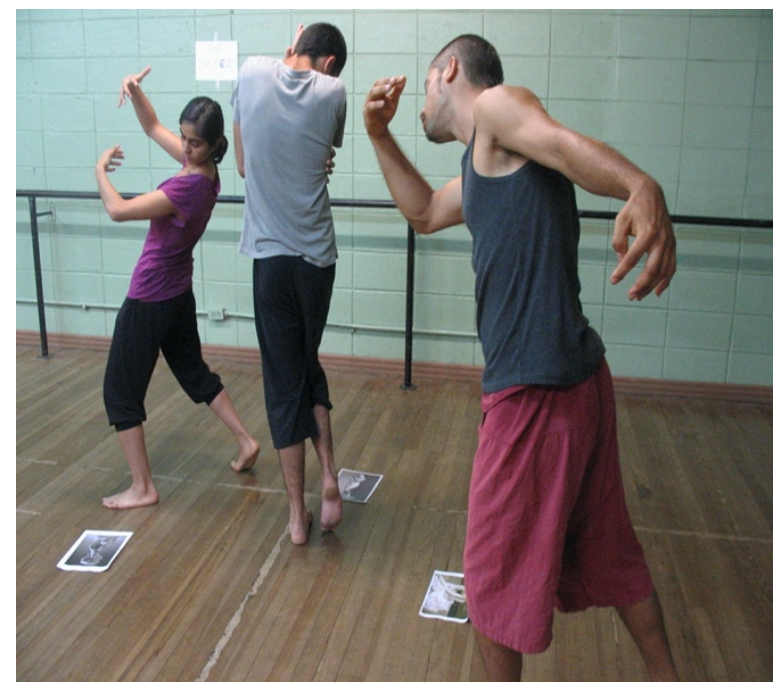

Foto: Ipojucan Pereira

Como um centro pelo qual poderiam passar várias trajetórias, cada aluno deveria, depois de um tempo de experimentação, optar por uma postura de partida e outra de chegada, que organicamente representassem a história pretérita e futura da postura tomada da imagem escultórica e plasmada no corpo. À medida que se interage com a imagem escultórica, busca-se preencher corporalmente as suas lacunas e indefinições. O caminho é conhecer e reproduzir por meio dos gestos e postura corporal, os ritmos, as intenções presentes nos traços 
assimétricos da escultura.

Com essa metodologia de criação, a partir da observação e experimentação corporal das características físicas e concretas da forma escultórica, trabalhamos indiretamente com o conceito de cinesfera. Sem poderem se deslocar pelo ambiente, como se estivessem encerrados num volume geométrico fixo, os participantes foram obrigados a explorar uma área "interna imaginária [como de uma] esfera [que] pode-se tocar com as mãos e pés e pode-se alcançar todos os seus pontos" (Laban, 1990, p. 85). Isso criou uma ideia de um espaço como se fosse um dado pré-existente e anterior ao corpo que ela contém, e aos movimentos que a ocuparão, da mesma maneira que um invólucro vazio espera de ser preenchido por algum material. Estabelecemos com esse procedimento a primeira abordagem quanto à reflexão sobre os vetores espaciais.

Com a falta de referencialidade a um contexto específico, o grau de abstração se tornou elevado, por conta do leque de possibilidades em se definir uma combinação que resultasse numa possível narrativa. Essa micro-partitura de ações passou a funcionar como um tipo de mascaramento, um foco que obrigava o intérprete a manter a sua concentração na sustentação e na manipulação de algo com o qual a sua totalidade psicofísica poderia ficar completamente envolvida. O procedimento procurou encaminhar a observação do aluno para o conflito plasmado nas incongruências, ambiguidades e oposições das linhas e relevos, que se configurou um estímulo para o incremento do potencial de caracterização por meio da adaptação da fisicalidade aos desenhos e traços requeridos pelas imagens escultóricas.

Após a criação dessa pequena célula de movimentação, e para dar início a um pensamento direcionado à composição de partituras mais complexas, adaptamos um procedimento descrito pelo ator Yoshi Oida, no livro o Ator Invisível (2001): a partir da proposta da construção de um personagem do externo para o interno, Oida procura demonstrar a conexão por meio do movimento entre uma ação estritamente física e a emoção. O ponto de partida inicial é a construção de uma sequência de posturas corporais - sem relação de causalidade entre elas -, com a concomitante concentração e observação das transformações internas 
e externas ao corpo, como consequência da dinamização sofrida a partir do transcurso em fluxo contínuo pela execução desse trem de posturas.

Primeiramente, os alunos foram orientados a repetir sem cessar a sua sequência, começando da postura escolhida para ser o ponto de partida, passando pela postura estabelecida como ponto médio e alcançando a terceira postura que punha um fim à trajetória do movimento. Ao chegar nesse ponto final, desmanchava-se a forma escultórica assumida e colocava-se o corpo numa postura neutra (posição anatômica), para novamente desenhar no físico a imagem escolhida como ponto de partida e refazer mais uma vez o percurso da sequência.

O trabalho inicia-se primeiramente a partir da posição estática, com uma sensibilização que expande a consciência para a pele, percebendo o contato com a roupa, com o ar, com o chão, levando a atenção para os ritmos físicos presentes no fluxo da respiração, nos batimentos cardíacos, nos movimentos involuntários. Desse ponto, o aluno experimenta sair do estático por meio desses impulsos corporais, sem planejar nenhuma ação, deixando que estes o guiem. É uma busca de uma condição em que o estudante cede, observa e age, como num permanente devir no qual não se sabe qual será o evento seguinte.

Durante a execução da sua micro partitura, os participantes foram orientados a manterem uma concentração sem focalização nos pensamentos, sensações e sentimentos que ocorriam em função da movimentação do corpo dentro desse circuito. O intuito era conseguir atingir um patamar de relaxamento e concentração que permita deixar que os estímulos externos encontrem livre acesso ao organismo. Esse estado de prontidão coloca o aluno em condições de observar a sua reação diante de um estímulo exterior, tal como uma sonoridade externa, ou objetos, imagens etc., e perceber a partir disso qual é a ação justa, que não necessariamente precisa estar correlacionada com o que a provocou.

Quando já estavam conseguindo se entregar a esse fluxo contínuo de repetição, foi pedido que cada um interferisse em sua própria corrente dinâmica, explorando ritmos variados e observando como essas intervenções alteravam tanto o movimento externo quanto interno, referente às sensações, sentimentos 
e pensamentos. Ainda dentro dessa proposta de transformação do movimento pela repetição, os alunos também foram instruídos a experimentar a ampliação e a redução como fatores de modificação do fluxo dinâmico.

Figura 04 - Alunos executando sequências de células de movimentação. Oficina La Partitura como Máscara (2014)
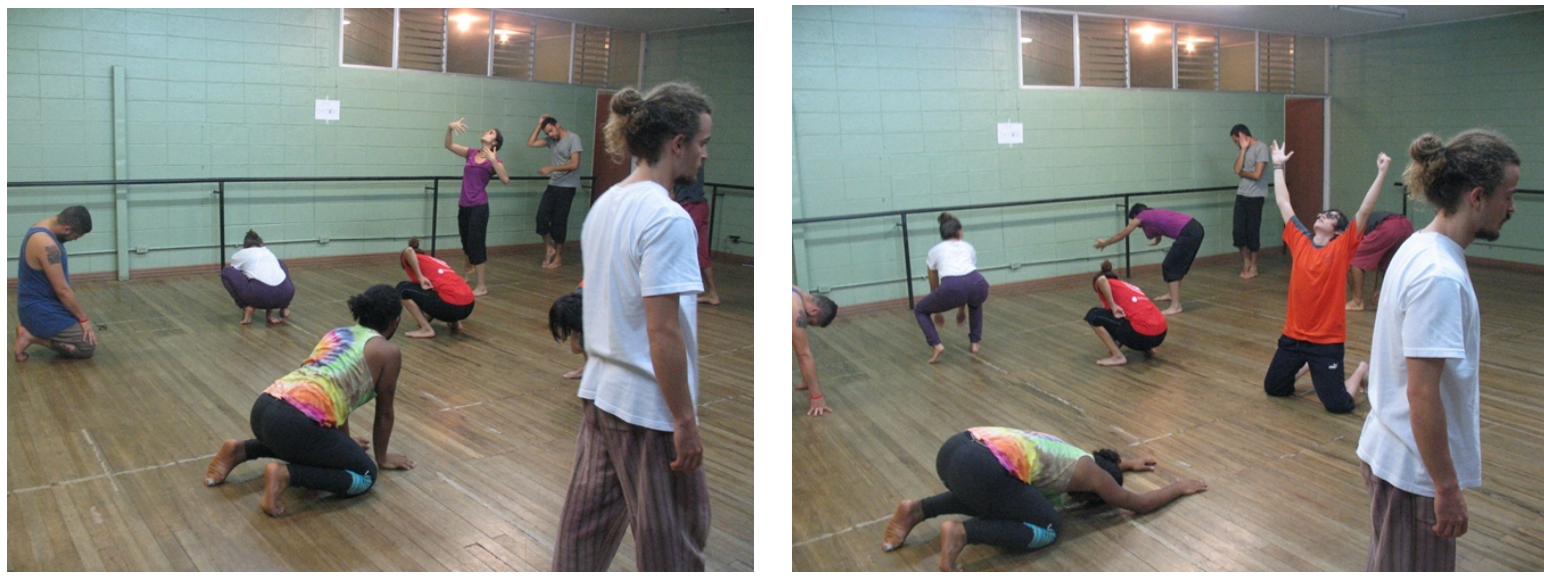

Foto: Ipojucan Pereira

Depois dessa experiência, foi pedido então que cada um escolhesse uma outra imagem e iniciasse com ela o mesmo trabalho, ou seja, gerar a partir dela uma segunda sequência, explorar as transformações dinâmicas por meio da repetição, ampliação e redução, observar as reações internas durante a execução e fazer pequenas intervenções relativas ao tempo e a energia empregada no movimento (ver Figura 4). A proposta a partir desse ponto era que cada um escolhesse uma ordem para executar as células de movimentação, sequenciado ambas para que constituíssem uma pequena partitura.

Havia de ser mantido o rigor na execução das trajetórias previstas, sem que nenhum ajuste fosse feito, por mais que a passagem de uma micro partitura para outra parecesse truncada ou sem sentido lógico. De fato, esse momento era o ponto fulcral sobre o qual nos debruçávamos nessa etapa, pois ele abria uma oportunidade de investigação acerca desse intervalo secundário, que não representa nada a não ser a passagem entre dois momentos expressivos. A proposição aos alunos era que iríamos encarar esse espaço, vazio de propostas, como repleto de estímulos para a criação. 
Cada um deveria dessa maneira observar o que o corpo fazia no intervalo entre o fim de uma micro partitura e o início da posterior. A cada repetição da sequência completa também não deveria ser negligenciada a passagem entre o final da partitura e a sua retomada, pois da mesma forma não estava prevista nenhuma movimentação partiturada para esse percurso. Esses espaços vazios se configuravam dessa maneira como abertos ao improviso de movimentos e dinâmicas, compondo junto com a parte já codificada uma partitura com porosidade suficiente para acolher os acasos e indeterminações causados pelos fluxos de criação internos e externos. O programa geral de atividades para o primeiro encontro encerrou-se nesse ponto, para a sua continuidade e conclusão no encontro seguinte.

\section{Etapa 3: Exploração de partituras no espaço além de si mesmo}

A partir desse patamar alcançado demos início uma outra etapa, que versou sobre o espaço "fora dessa esfera imediata [...] mais amplo, o 'geral', no qual o homem [...] tem que pisar fora das bordas de sua esfera imediata e criar outra nova, a partir de sua nova postura" (Laban, 1990, p. 85, grifo do autor). Para detonar o trabalho com esse território situado além dos limites do espaço pessoal, e no qual habitam os outros, sejam eles orgânicos ou inorgânicos, foi necessário promover a transição do individual para a articulação coletiva do espaço. Por meio dos deslocamentos espaciais, resolvi lançar mão de alguns expedientes que facilitassem a compreensão da problemática que envolve as orientações do corpo no espaço. O apoio veio das reflexões do diretor do teatro da Bauhaus, Oskar Schelemmer, ao observar que na exploração da arquitetura do movimento, a partir das leis do espaço cúbico por meio da planimetria, da "geometria do chão, do acompanhamento das retas, das diagonais, do círculo e da curva, desenvolve-se quase que espontaneamente uma estereometria do espaço através da figura móvel que dança." (Granero, 1995, p. 145). 
Numa composição coreográfica, a planimetria e a estereometria8 estão relacionadas para dar suporte ao fluxo de movimento do dançarino, sendo a primeira a representação no plano do chão dos deslocamentos e localizações, e a segunda a transposição dessa geometria para a espacialidade dos corpos. Um dos procedimentos empregados por Schelemmer era a marcação sobre o assoalho do palco das trajetórias e posições dos bailarinos (ver Figura 5), conectada às projeções estereométricas da sala, que propiciava tanto a visualização de todas as áreas no solo a serem exploradas nos deslocamentos, quanto a percepção das linhas invisíveis que subdividiam o espaço e que orientavam a gestualidade corporal. Figura 5 - Oskar Schlemmer: "Figura no Espaço com Geometria Plana e Delineações
Espaciais" $(1927)^{9}$

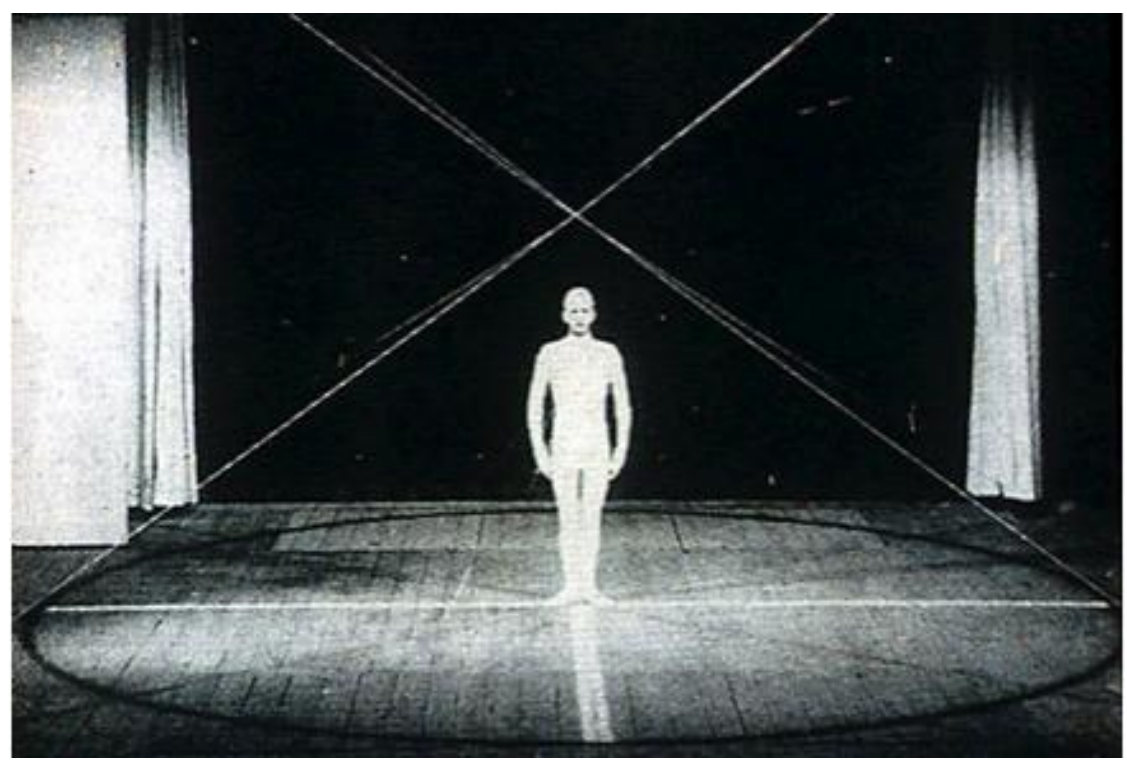

Partindo da oposição entre a verticalidade estática da figura humana e o plano horizontal do chão, essa ortogonalidade se desdobra tridimensionalmente pelo espaço quando o corpo, nas suas torções em torno de seu próprio eixo, se

\footnotetext{
8 A estereometria, ou geometria do espaço, é um ramo da matemática que estuda o volume dos sólidos geométricos e que nos auxilia na medição do mundo tridimensional que nos rodeia. A planimetria é a representação em um plano de algum espaço tridimensional; os pontos medidos são projetados sobre uma superfície horizontal.
}

9 Disponível em: http://www.studyblue.com/notes/note/n/midterm-images/deck/966504. 
movimenta criando linhas diagonais, ampliando os efeitos dinâmicos e expressivos. No entanto, para Schlemmer, colocar a primazia somente nessas relações matemáticas era mecanizar movimento, o que o levou a colocar no centro das suas criações "o ser humano, cujos movimentos e emanações criam um espaço imaginário [...], e o espaço cúbico-abstrato é tão somente a estrutura horizontal e vertical para [...] os impulsos físicos ${ }^{10 "}$ (Schlemmer, 1961, p. 25, grifo do autor). A conexão entre a forma humana e as extensões da arquitetura tornou o espaço e o corpo os elementos principais das matrizes que organizam as partituras e coreografias das obras de Schlemmer.

A partir dessas propostas envolvendo o uso da planimetria e da estereometria foram desenvolvidos alguns procedimentos para o trabalho com os participantes das oficinas. A primeira providência foi a definição na sala de ensaio de uma área que simulasse a situação de um palco cênico genérico, com a preocupação de que essa configuração fosse desvinculada de modelos prévios de construção cenográfica, e com vocação suficiente para ser percebida e operacionalizada como um local abstrato e flexível para receber qualquer narrativa cênica (ver Figura 6).

\section{Figura 6 - Exploração da área planimétrica e estereométrica Oficina La Partitura como Máscara (2014)}

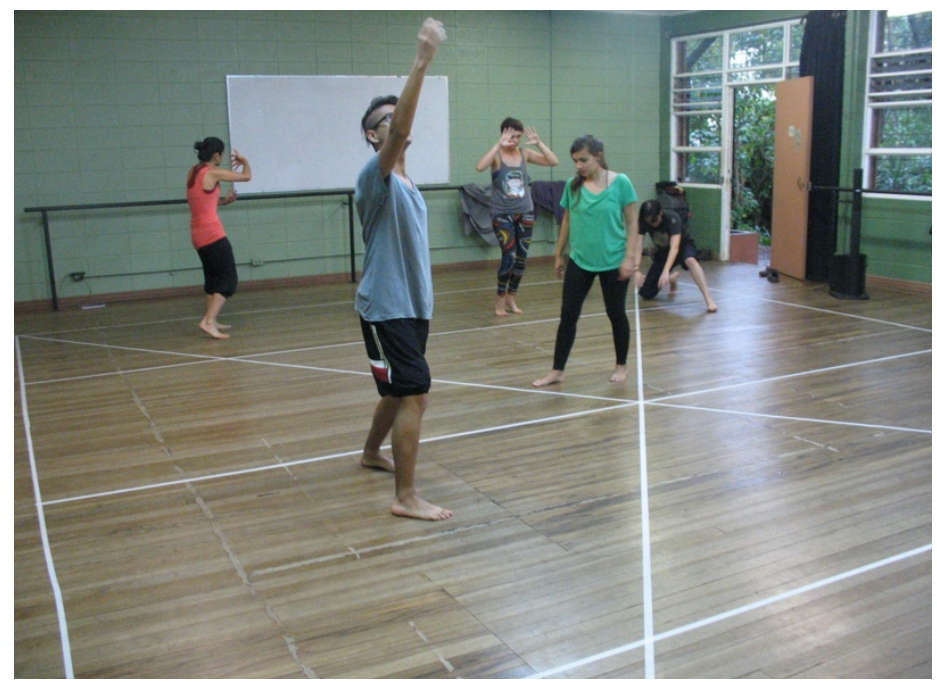

Foto: Ipojucan Pereira

$10[\ldots]$ the human being, whose movements and emanations create an imaginary space. [...] Cubical-abstract space is then only the horizontal and vertical framework for [...] the psychical impulses [...]. (Tradução nossa) 
Para a disposição dessa área, foi traçado um retângulo com fita crepe no centro da sala de ensaio, deixando o seu contorno, ao redor das suas arestas, livre para a circulação dos jogadores (essa área funcionava como uma espécie de coxia). Dos cantos internos do interior retangular, foram traçadas duas diagonais que se cruzavam no centro. Paralelamente aos lados do retângulo foram dispostas três linhas horizontais equidistantes e três verticais, que conservavam o mesmo distanciamento entre si. Obtivemos dessa maneira uma planimetria esquemática, pois não havia nenhum compromisso com a projeção das medidas ortogonais da sala de ensaio sobre o desenho traçado no chão.

Como aquecimento prévio, os alunos foram orientados a se deslocarem sobre essa grade, procurando observar as relações de equilíbrio, tensão, proporção e composição entre as posições ocupadas pelos seus corpos. O foco principal era a percepção aos estímulos que as condições desse formato de enquadramento incitavam às dinâmicas corporais. Após essa sensibilização, os alunos se dispuseram em volta do retângulo e um dos jogadores ocupou o centro. A ideia é que esse retângulo fosse encarado como um assoalho que estivesse apoiado sobre um único pilar, posicionado exatamente no centro. Como se fosse uma balança instável, qual peso colocado na superfície do assoalho fora desse ponto em seu centro, faria o chão oscilar e desequilibrar todo o conjunto.

Dessa maneira, quando o jogador que estava colocado no centro desse tablado iniciava uma caminhada sobre o mesmo, ou quando alguém posicionado a volta do mesmo pisava dentro dessa área, se instaurava um desequilíbrio que obrigava a todos que estavam colocados do lado de fora tomarem uma atitude e entrarem para ocupar pontos estratégicos, e assim manter a relação de sustentação do tablado por meio do equilíbrio dos pesos colocados sobre o mesmo. Cada rodada do jogo só chegava ao fim quando todos haviam ocupado uma posição dentro da área retangular, e conseguiam sair conjuntamente sem desequilibrar o tablado.

No procedimento seguinte, a turma foi dividida em dois grupos que se revezaram nas funções de atuadores e espectadores, isto é, enquanto um grupo 
executava uma tarefa o outro o observava. Para esse exercício, a ideia do tablado equilibrado sobre uma coluna foi desfeita e retomamos a marcação estereométrica traçada no chão, dentro do retângulo, conservando apenas o pensamento sobre a distribuição equânime dos corpos no espaço, e o local mais adequado para se desenvolver as ações cênicas. Essa reflexão abarcava inclusive a presença do espectador (representado pelo grupo que desempenhava essa função), que estava posicionado frontalmente para assistir ao desempenho dos jogadores.

Ao ouvir uma instrução de comando específica, o grupo a ser primeiramente observado deveria entrar no espaço retangular de jogo em conjunto e se distribuir equilibradamente sobre o traçado de linhas e diagonais. A partir de uma pausa inicial, percebida pela atenção ao coletivo, cada membro do grupo começava a executar a sua partitura completa de ações construída no encontro anterior (inclusive levando em consideração os espaços vazios). Ao findar de toda a movimentação, o grupo se retirava conjuntamente para a área externa ao retângulo, que representava as coxias (ver Figura 7).

Figura 7 - Relação entre partitura e ambiente. Oficina “La Partitura como Máscara” (2014)
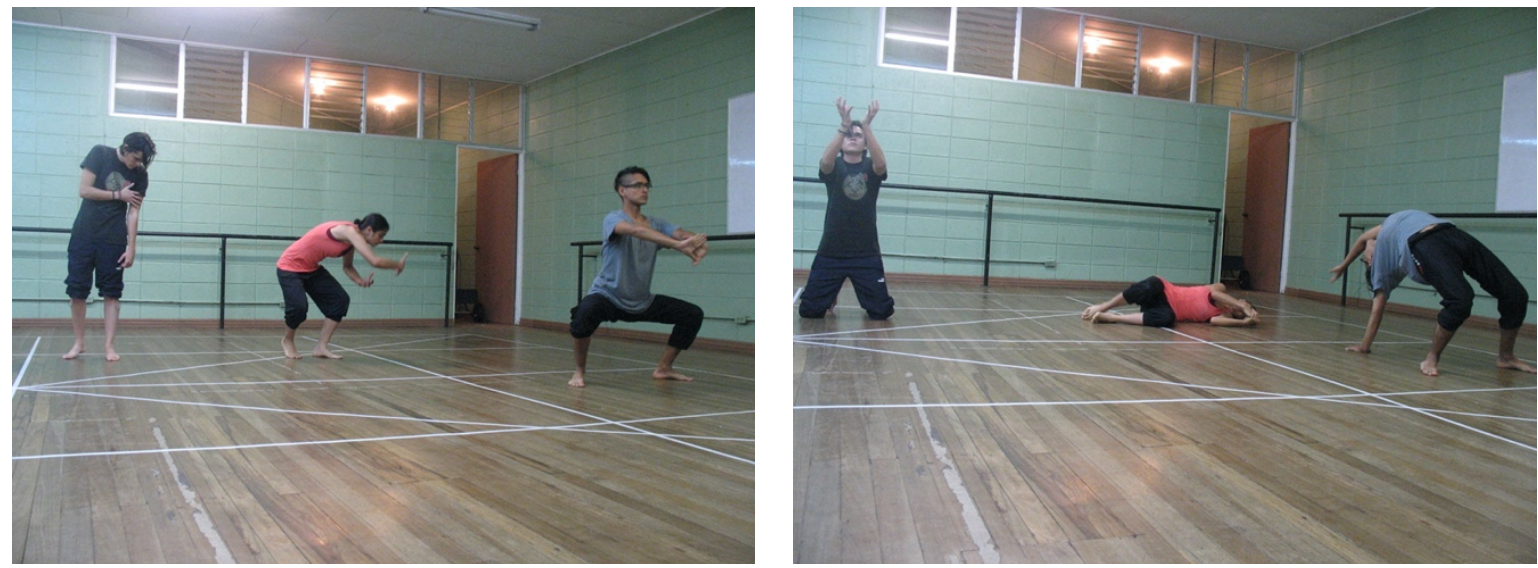

Foto: Ipojucan Pereira

Como no encontro anterior, a sequência de ações ainda foi realizada sem deslocamentos pelo espaço, para que cada um dos participantes explorasse possibilidades de investigação e entendimento das leis matemáticas que 
construíam a arquitetura na qual se encontrava imerso. Essa restrição imposta a um livre intercurso pela área demarcada foi compensada pela necessidade de submeter a corporeidade aos eixos vertical, horizontal e diagonal representados pelas projeções estereométricas no chão, propiciando uma investigação mais profunda da espacialidade corporal.

No procedimento seguinte, foi proposto então a exploração do deslocamento do corpo pelo espaço conjugado com a execução da partitura construída. A proposição foi que a sequência construída no primeiro encontro fosse desmembrada e que as duas células de movimentação (cada uma relativa a uma das imagens escultóricas) ficassem independentes uma da outra. Essas células seriam intercaladas com ações de deslocamento, configurando uma sequência que obedeceria ao princípio de que a ligação entre dois percursos diferentes deveria ser feita por uma célula de movimentação executada numa posição fixa (ver Figura 8).

Figura 8 - Partitura de deslocamento. Oficina La Partitura como Máscara (2014)
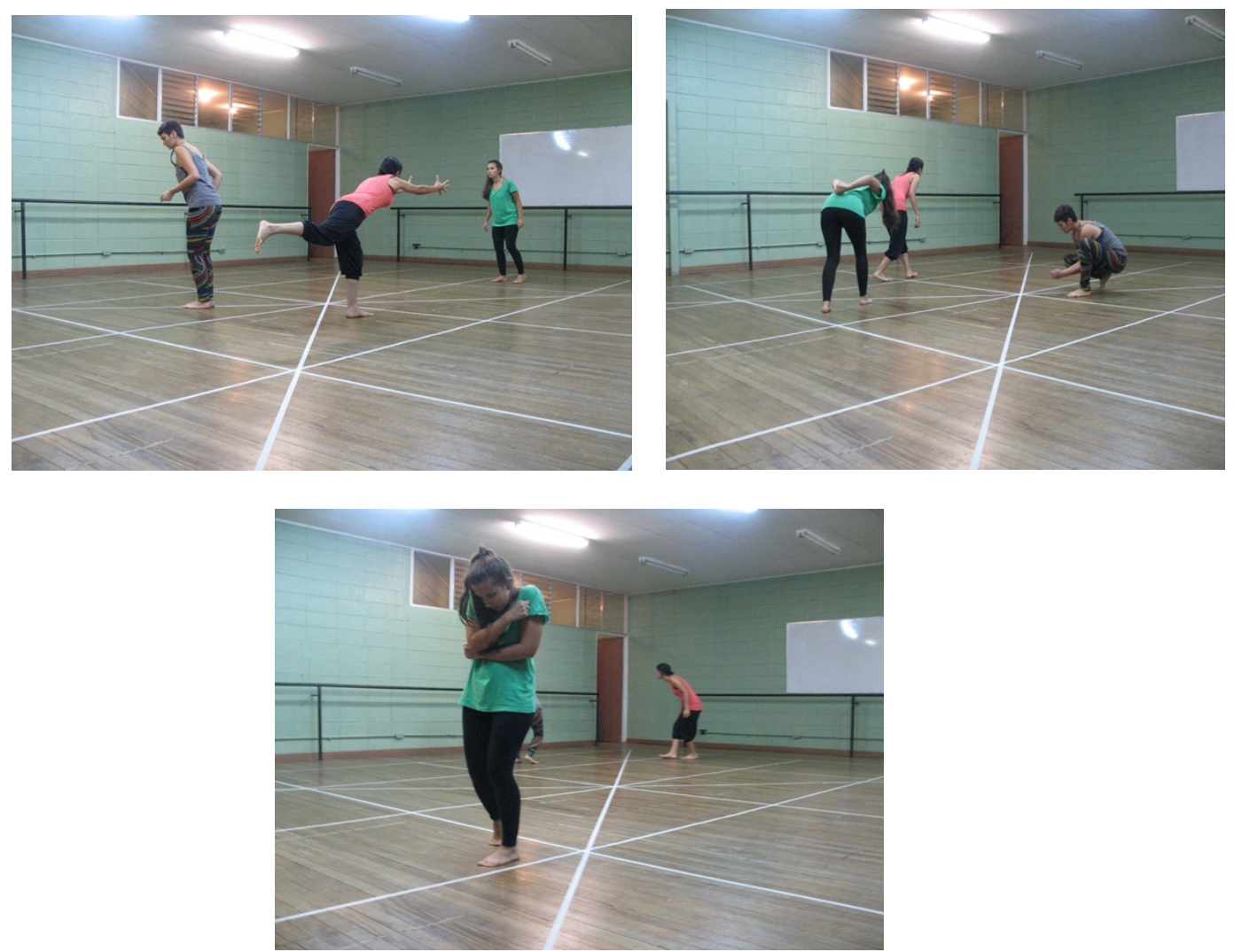

Foto: Ipojucan Pereira 
Na alternância entre ação em curso e ação no mesmo local, era permitido realizar as células de movimentação mais de uma vez, porém os percursos só poderiam acontecer uma única vez. Essas regras objetivavam a criação de uma partitura mais complexa, na qual o corpo executaria tanto ações em deslocamento quanto em posição estática. Depois que cada um fixou a sua partitura, a turma foi dividida em novamente para que uma parte apresentasse à outra os resultados alcançados.

Foi conduzida uma reflexão com o auxílio dos colegas colocados como plateia, direcionada tanto para as escolhas compositivas de cada participante que se apresentou, com relação tanto à totalidade do conjunto, quanto às conexões que surgiram entre as sequências de ações de cada um. Concluiu-se, por exemplo, que os sentidos do espectador não só se determinam por meio dos diferentes recursos da encenação, como também a partir da consideração da unidade do espaço teatral, a partir do tipo de relação que a arquitetura promove entre a sala e a cena. Mesmo sendo um desenho planimétrico de solo esquemático, o estímulo serviu a um pensamento tridimensional de que o corpo cênico constrói algo a ser visto pelo público.

\section{Etapa 4: Criação, apresentação e finalização do processo}

Para finalizar, foi retirada a marcação planimétrica no chão, não havendo mais a restrição imposta pela mesma, esperando-se que cada participante articularia as questões geométricas em função das suas próprias opções criativas. Originou-se a partir daí um improviso coletivo, sem palavras, no qual cada aluno executava a sua partitura cênica - composta tanto por ações de deslocamento quanto por gestos - enquanto se mantinha atento a tudo o que acontecia no ambiente, tanto em si como circundante. Durante a movimentação dos alunos pelo espaço, foi veiculada uma sonoplastia constituída de ruídos e sons diversos, que representava mais um estímulo à percepção. Esse contexto alimentava às variações dinâmicas da partitura cênica de cada um. 
Figura 9 - Apresentação do resultado da oficina no teatro da Escuela de Artes de la UCR. Oficina La Partitura como Máscara (2014).

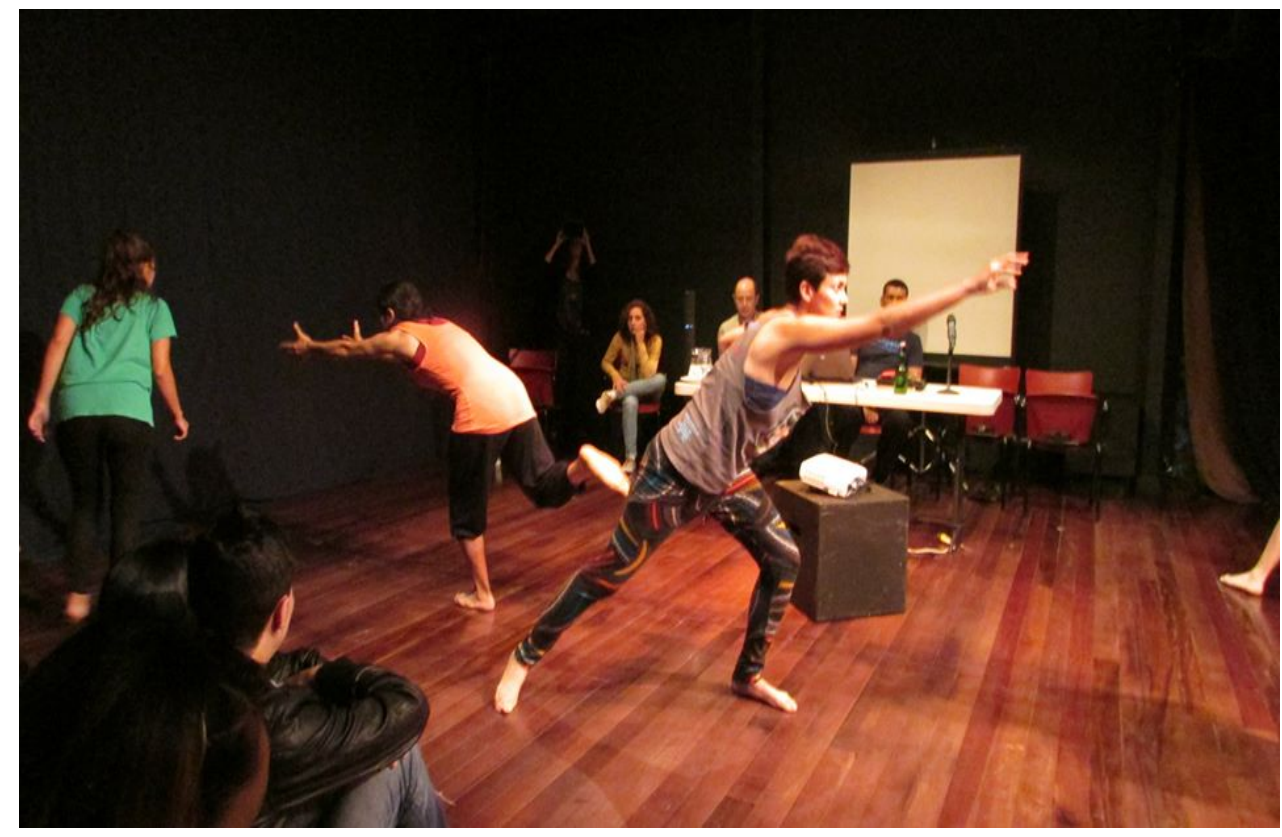

Foto: Ipojucan Pereira

Essa proposta de jogo entre a partitura e o ambiente foi levada ao teatro da Escuela de Artes de la UCR com a presença do publico, que veio a se tornar mais um estímulo posto no espaço e que devia ser incorporado ao jogo. A partitura cênica era executada exatamente como foi ensaiada, e a espacialidade configurada pela presença de todos os elementos presentes no ambiente (ver Figura 9).

Esses procedimentos instauraram uma outra dinâmica de exploração do espaço, desdobrando-o como uma proposta em que podem ser lidas uma poética e uma estética fomentadora de um processo criativo. Os seus indicativos apontam para a importância do tipo de espacialização sofrida pelos signos cênicos, problematizando a função do espaço não só de ser continente de eventos diversos, mas de criar uma identidade e resultar num corpus artístico homogêneo e coerente a ser comunicado à plateia, sobretudo quando imprime essa ação unificadora. É o princípio da ideia de uma dramaturgia que se faz na articulação das linhas, nas texturas das superfícies, nas variações de dinâmicas, ou seja, na "relação de todos os sistemas significantes usados na representação e cujo arranjo 
e interação formam a encenação." (Pavis, 2001, p. 409).

$\mathrm{Na}$ apreciação final da oficina os relatos dos alunos apontaram para uma compreensão mais aprofundada das possibilidades que o trabalho sobre o espaço e as partituras físicas pode vir a contribuir para a criação do ator. Como as minhas incursões investigativas com esses procedimentos na pesquisa de doutorado, até então, sempre foram aplicadas em atores profissionais, contar com a participação desse outro segmento significou explorar em maior profundidade o viés pedagógico do mascaramento espacial.

\section{Referências}

AMARAL, Ana Maria. O Ator e seus Duplos: máscaras, bonecos e objetos. São Paulo: Ed. SENAC, 2002.

BOGART, Anne. The Viewpoints Book: a practical guide to viewpoints and composition. New York: Theatre Communications Group, 2005.

ERULI, Brunella. O Ator Desencarnado. Marionete e Vanguarda. Revista Móin-Móin, Jaraguá do Sul, SCAR/UDESC, ano 4, vol. 5, p. 11-25, 2008.

GRANERO, Maria Victoria V. Machado. A Aventura do Teatro da Bauhaus. São Paulo, 1995. Tese (Doutorado) - Escola de Comunicações e Artes, Universidade de São Paulo, 1995.

LABAN, Rudolf. Dança Educativa Moderna. São Paulo: Ícone, 1990.

OIDA, Yoshi. O Ator Invisível. São Paulo: Beca Produções Culturais, 2001.

PAVIS, Patrice. Dicionário de Teatro. São Paulo: Perspectiva, 2001.

RENGEL, Lenira. Dicionário Laban. São Paulo: Annablume, 2003.

SCHLEMMER, Oskar. Man and Art Figure. In: GROPIUS, Walter (ed.). The Theater of the Bauhaus. London: Eyre Methuen Ltd., 1961, p. 17-46.

SILVA, Ipojucan Pereira. Mascaramento Espacial: um processo criativo envolvendo a espacialidade corporal do ator. São Paulo, 2015. Tese (Doutorado) - Escola de Comunicações e Artes, Universidade de São Paulo, 2015. 
SILVA, Laís Marques. Escuta-Ação: pistas para a criação do ator em diálogo com o Sistema dos Viewpoints. São Paulo, 2013. Dissertação (Mestrado) - Escola de Comunicações e Artes, Universidade de São Paulo, 2013.

Recebido em: 01/07/2020

Aprovado em: 05/08/2020 